\title{
Subjective Outcomes Assessment in Chronic Rhinosinusitis
}

\author{
Ingo Baumann*
}

Department of Otolaryngology, Head and Neck Surgery, Im Neuenheimer Feld 400, D-69120 Heidelberg, Germany

\begin{abstract}
The treatment of chronic rhinosinusitis (CRS) requires an increasing use of medical and economic resources. Therefore, the assessment of objective and subjective outcome of different treatment strategies is of considerable interest.

Validated quality of life (QOL) instruments are one important means to assess subjective outcome of the patients. Frequently used generic instruments are the Short Form 36 Health Survey (SF-36) for prospective evaluations and the Glasgow Benefit Inventory (GBI) for retrospective evaluations. Normative data and numerous comparative data sets collected from various diseases are available for the SF-36.

Disease-specific QOL instruments for CRS have been developed over the last 15 years. In this review 11 disease-specific instruments are discussed. Only four of these instruments cover all four main symptoms of CRS and are completely validated as well. Most frequently used instruments (Sino-Nasal Outcome Test, SNOT-20; Chronic Sinusitis Survey, CSS) do not query all the main symptoms of CRS.
\end{abstract}

Keywords: Quality of life, measuring instrument, validation, SF-36, SNOT-20.

\section{INTRODUCTION}

Chronic rhinosinusitis (CRS) is a common health condition in industrial countries concerning $10-15 \%$ of the German population [1]. In the US it was the most frequently reported chronic disease in a representative cohort of 100.000 adults participating in the National Health Interview Survey 1988 [2]. Negative effects of CRS on QOL of the patients have frequently been underestimated. Nevertheless, many patients report higher impacts of CRS on QOL dimensions like bodily pain or social functioning compared with other diseases like angina pectoris, pulmonary emphysema or chronic bronchitis [3].

Economic impact of CRS has rarely been investigated. In 2006, nearly 45.000 patients with CRS were operated in German hospitals [4]. In 1996, the healthcare expenditures for sinusitis in the US were 5.8 billion Dollars [5]. Gliklich and Metson [6] performed a break-even analysis and calculated a time period of 7 years until amortization of treatment costs can be achieved by reduced postoperative use of resources.

Under these conditions effective and successful treatment of CRS has an increasing medical and economic importance. The outcomes assessment of CRS treatment have been discussed in the literature for many years. In 1942, the revision surgery rate in 190 patients after transfacial extranasal procedures was nearly $31 \%$ [7]. Modern functional endonasal sinus surgeries (FESS) result in stable subjective success rates between $70 \%$ and $92 \%$ [8-10].

*Address correspondence to this author at the Department of Otolaryngology, Head and Neck Surgery, Im Neuenheimer Feld 400, D-69120 Heidelberg, Germany; Tel: +49(0)6221-56 6705; Fax: +49(0)6221-567478; E-mail : ingo.baumann@med.uni-heidelberg.de
Until the nineteen-nineties the evaluation of success was straitened to the reporting of complications, revision surgery rates etc. It was postulated that normal and noninflammatory endoscopic clinical findings were always a successful result even for the patient. However, frequently strong divergences between clinical findings and subjective patient reports had to be noted [10]. Furthermore, computed tomography (CT) which is the most important imaging method in these patients could not establish significant correlations between imaging and symptom severity.

Since the nineteen-eighties quality of life (QOL) instruments were systematically developed and validated for use in clinical medicine to achieve the goal of measuring the subjective outcome of the patients. The first instruments for use in patients with CRS were developed in the nineteennineties. In the following general and disease-specific QOL instruments which are in use in patients with CRS are presented.

\section{GENERAL (GENERIC) INSTRUMENTS}

General instruments are applicable in different diseases. They measure general QOL and/or general health status of the patients. Different diseases can be compared regarding their impact on general QOL.

\section{SHORT FORM 36 HEALTH SURVEY (SF-36)}

The SF-36 questionnaire consists of 36 single items which form eight scales [11]. Every single item is a part of a scale or forms a scale by itself. For every single item the patient has to mark that given answer mostly approximating to his or her subjective experiences. The scales are:
1. Physical function
2. Role physical 
3. Bodily pain

4. General Health

5. Vitality

6. Social function

7. Role emotional

8. Mental health

The SF-36 is the most frequently used instrument worldwide for the measurement of general health-related QOL [12].

Several SF-36 studies including one study by our group demonstrated improved health-related QOL after endonasal sinus surgery in patients with CRS [13-15]. A prospective longitudinal study detected significantly improved scores in 6 out of 8 scales three years after surgery [16].

The SF-36 questionnaire has frequently been used concurrently with disease-specific instruments. Thus, in a prospective controlled study medical as well as surgical therapy of CRS lead to QOL improvement in the SF-36 and in the SNOT-20 while no differences in treatment success between the two cohorts could be detected [17].

\section{SHORT FORM 12 HEALTH SURVEY (SF-12)}

The SF-12 is a shortened version of the SF-36 which contains items from all eight SF-36 scales. Two summary scales were established: physical and mental summary score. The SF-12 is a reliable, valid and sensitive QOL instrument [18]. An improvement of physical and mental summary scores was demonstrated after FESS in patients with CRS [19].

\section{CHILD HEALTH QUESTIONNAIRE (CHQ)}

If QOL measurements in childhood are performed it is always a matter of discussion whether the patients (children) or their parents are the adequate persons to answer the questionnaire. Frequently, the parents serve as proxies for their children as they might have a better understanding for the evaluated subject and might better understand the questionnaire. While growing up children are increasingly competent to assess their health status [20].

The CHQ offers a 50-item version which is filled out by the parents as proxies for their children (CHQ-50PF, parent form) and an 87-item version to be filled out by the child itself (CHQ-87CF, child form). The questionnaire has 14 scales being assigned to two summary scores which are the physical and the psychosocial health score. The CHHQ-50PF is available in 60 languages. Normative values are available for the Australian and the US populations [21, 22].

Compared with the normal population and with other chronic paediatric diseases children with recurrent CRS showed a significantly reduced QOL in the scales of the CHQ [23].

\section{GLASGOW BENEFIT INVENTORY (GBI)}

The GBI was developed in 1996 in order to evaluate outcomes of surgical otorhinolaryngologic interventions [24]. It consists of 18 items which query changes of health status after an intervention. Choices of answers per item on a five point Likert scale are: extremely positive, positive, no change, negative, extremely negative. One overall scale and three subscales for the assessment of general health, social support and physical functioning are calculated from the 18 single items. The scores for the GBI range from -100 to +100 , with positive scores indicating improvement in QOL and benefits, whereas 0 indicates no change and negative values a change for the worse.

The GBI was used for reporting the outcomes of many surgical procedures in the field of otolaryngology like tonsillectomy, rhinoplasty, or vestibular schwannoma surgery [25-27].

The benefit of FESS in CRS patients is shown in Table 1. In addition, the study of Salhab [28] revealed a higher benefit of FESS for CRS with polyposis nasi compared with CRS without polyposis.

\section{DISEASE-SPECIFIC INSTRUMENTS}

\section{Nasal Symptom Questionnaire, synonym: Fairley Nasal Symptom Score}

The Nasal Symptom Questionnaire was the first validated QOL instrument to measure subjective nasal impairments [31]. It was developed on the basis of a non-validated instrument by Lund [32]. The instrument has 12 items which can be assessed on a four point Likert scale from 0 (no problem) to 3 (severe problem). Fairley performed a validation on 411 patients which showed a good reliability (Cronbach's alpha $=0,776$ ) and proved a good content validity and construct validity [33].

The Nasal Symptom Questionnaire was used in different studies on patients with CRS and nasal septal surgery [34, 35].

\section{Rhino-Sinusitis Diability Index (RSDI)}

The RSDI was developed in 1997 by Benninger and Senior [36] with the goal to combine the assessment of general health status and disease-specific QOL in CRS patients in one instrument. Therefore, when using the RSDI the application of a general QOL instrument is not obligatory.

Table 1. Glasgow Benefit Inventory Results in CRS Patients

\begin{tabular}{|c|c|c|c|c|c|}
\hline & $\mathbf{n}$ & Overall Benefit & General Health & Social Support & Physical Functioning \\
\hline \hline Salhab, [28] & 77 & 11,1 & 12,5 & 0 & 0 \\
\hline Baumann, [29] & 82 & 22,6 & 26,8 & 2,9 & 23,7 \\
\hline Newton, [30] & 50 & 25,0 & 29,2 & 0 & 16,7 \\
\hline
\end{tabular}


The RSDI consists of 30 items. Validity, reliability and responsiveness of the instrument have been proved [37]. It has been used in a number of clinical studies in CRS patients [38-41].

\section{General Nasal Patient Inventory (GNPI)}

The GNPI was published in 2003 by Douglas et al. [23]. It consists of 45 items which were specified by 211 patients in an open questioning. Because of the high number of items specificity of the GNPI is reduced. Furthermore, the length of the questionnaire might potentially reduce the compliance of the patients to fill out the questionnaire. These might be the reasons for the rare using of the GNPI.

\section{Sinonasal-5 Quality of Life Survey (SN-5)}

The SN-5 was developed for QOL assessment in children with CRS [42]. The questionnaire is filled out by the parents who serve as proxies for their children. Five QOL domains are investigated: paranasal sinus infection, nasal obstruction, restriction of activities, allergic symptoms, and emotional impairment. Reliability, validity and responsiveness of the SN-5 could be demonstrated. In a clinical study using the SN-5 a long-lasting significant improvement of sino-nasal symptoms after adenoidectomy or paranasal sinus surgery in children could be demonstrated $[43,44]$.

\section{Sino-Nasal Assessment Questionnaire 11 (SNAQ-11)}

The SNAQ-11 was validated in the year 2000 [45]. It is noteworthy that three items of this questionnaire (blocked nose, nasal congestion, and facial pain/pressure) are to be weighted by multiplying the item values with 3 respective 2 before calculating the overall score. The questionnaire covers all main symptoms of CRS. Comparing the results of the questionnaire with the results of SNOT-20 it showed higher post-operative score changes [46]. A Medline search revealed the use of the SNAQ-11 in three studies.

\section{Chronic Sinusitis Survey (CSS)}

In 1995, Gliklich and Metson developed the CSS [13]. Since then, this measuring instrument besides the SNOT-20 was the most frequently used instrument for the measurement of QOL in CRS patients. It contains six single items and has proven validity and reliability [47-49]. The CSS consists of two parts: a symptom-based and a medication-based part. Loss of smell as one major symptom of CSS is not implemented in the instrument. In contrast to other QOL instruments the time span but not the severity of symptoms is queried as this resulted in higher retest reliability during the development process of the instrument [13].

In patients with CRS the CSS demonstrated a high sensitivity to change. It could be verified that endonasal sinus surgery reduces nasal impairments of CRS patients [6, $13,37,47]$. Another study with this questionnaire dealing with cost-benefit analysis after endonasal sinus surgery revealed that the treatment of mild forms of CRS is more cost-effective when compared with the treatment of pansinusitis [49].

\section{Rhinosinusitis Quality of Life Survey (RhinoQoL)}

This instrument might be regarded as an enhancement of the Chronic Sinusitis Survey (CSS) since the questioning techniques as well as the authors of the questionnaires are identical. Atlas et al. [50] validated this 17-item instrument using the data of 50 patients. RhinoQoL was partially superior to the CSS. However, also RhinoQoL does not inquire smell disturbances which are one major symptom of CRS. Also in this instrument, the time span but not the severity of symptoms is queried. RhinoQoL was not used in further published studies until now.

\section{Sino-Nasal Outcome Test 20 (SNOT-20), SNOT-16 and SNOT-22}

Piccirillo et al. [51] developed and validated the 31-item Rhinosinusitis Outcome Measure (RSOM-31) which contains rhinosinusitis-specific and general items. A condensed 20-item version of this questionnaire called SNOT-20 (Sino-Nasal Outcome Test-20) was validated as well [52]. The latter questionnaire showed a higher patient compliance because of the lower time and effort for the patients. It queries 20 symptoms of rhinosinusitis which can be assigned to five subgroups (nasal symptoms, paranasal symptoms, sleep-related symptoms, social impairment and emotional impairment). The patients rate the severity of the symptoms on a 6-point Likert scale. The score of the SNOT20 is calculated by summation of all the symptom scores. Therefore, scale values of the SNOT-20 range from 0 to 100 . Additionally, patients can circle those 5 symptoms which have the highest impact on the impairment.

During the last years the SNOT-20 was increasingly used for QOL measurements in patients with CRS. Therapy of CRS with nasal steroids resulted in a reduction of SNOT-20 scores [53]. In a prospective, randomized study to compare medical versus surgical therapy of CRS the QOL instruments SNOT-20 and SF-36 did not detect significant outcome differences between the two therapeutic strategies [17].

Further studies investigated the impact of nasal polyposis in patients with CRS on the subjective outcome assessment of endonasal sinus surgery. While Ragab et al. [17] as a result of their study do not consider nasal polyposis as a prognostic factor; Deal and Kountakis [54] found that symptoms are more severe in nasal polyposis. Furthermore, they stated lesser improvements after surgery and a significantly higher rate of required revision surgeries when comparing polyposis patients with non-polyposis patients.

Another validated version named SNOT-16 was applied to investigate the impact of smoking on post-operative QOL in patients with CRS [55]. Smokers scored significantly higher scores compared with non-smokers indicating reduced QOL (27.5 vs 18.2; $\mathrm{p}<0.001)$.

The Clinical Effectiveness Unit of the Royal College of Surgeons of England published the National Audit of Surgery for Nasal Polyposis and Chronic Rhinosinusitis in 2003, reporting QOL data of 3128 patients collected in 2000 in 87 hospitals in England and Wales with the SNOT-22 [56]. Though SNOT-22 is a non-validated questionnaire in contrast with SNOT-20 it covers all the major symptoms of CRS by adding the items "nasal obstruction" and "loss of smell". All in all, a high contentedness with the results of paranasal sinus 
surgery was stated. Clinically significant QOL improvements for the whole cohort could be observed 3 and 12 months postoperatively. Nevertheless, between 3 and 12 months after surgery QOL scores showed slight deterioration of the scores whereas only polyposis patients showed stable significant improvement compared with the pre-operative scoring. Only $43 \%$ of the patients with CRS without nasal polyposis reported a stable improvement of their symptoms after 12 months while $32 \%$ rated their symptoms same or deteriorated when compared with the pre-operative situation. Therefore, polyposis patients might benefit more from paranasal sinus surgery than CRS patients without polyposis.

This review of the literature clearly shows that SNOT-20 and its derivates found wide acceptance in the analysis of health-related QOL in patients with CRS.

\section{PSYCHOMETRIC PROPERTIES OF DISEASE- SPECIFIC QOL INSTRUMENTS}

Instruments for the measurement of disease-specific QOL in CRS patients should cover at least the major symptoms of CRS. Furthermore, psychometric appropriateness should have been proven by validation of the instrument.

The major symptoms of CRS with or without nasal polyposis are listed in the European Position Paper on Rhinosinusitis and Nasal Polyps 2007 (EP ${ }^{3} \mathrm{OS}$ ) [57]. CRS is defined as inflammation of the nose and the paranasal sinuses characterised by two or more symptoms, one of which should be either nasal blockage/obstruction/ congestion or nasal discharge (anterior/posterior nasal drip) with or without facial pain/pressure as well as with or

Table 2. Major Symptoms of CRS and Psychometric Characteristics in Different Disease-Specific QOL Instruments; NR = Not Reported

\begin{tabular}{|c|c|c|c|c|c|c|c|c|}
\hline Instrument & Language & \multicolumn{4}{|c|}{ Main Symptoms of CRS } & \multicolumn{3}{|c|}{ Psychometric Characteristics } \\
\hline $\begin{array}{c}\text { Nasal Symptom } \\
\text { Questionnaire (Fairley, } \\
{[31] \text { ) }}\end{array}$ & English & $\mathrm{X}$ & $X$ & $X$ & $\mathrm{X}$ & $\mathrm{X}$ & $X$ & $\mathrm{X}$ \\
\hline $\begin{array}{l}\text { Sino-Nasal Assessment } \\
\text { Questionnaire } \\
\text { (SNAQ-11) } \\
\text { (Fahmy, [45]) }\end{array}$ & English & $\mathrm{X}$ & $X$ & $\mathrm{X}$ & $\mathrm{X}$ & $\mathrm{X}$ & $\mathrm{X}$ & $\mathrm{X}$ \\
\hline $\begin{array}{l}\text { Sinunasal-5 quality of } \\
\text { life survey (SN-5) } \\
\text { (Kay, }[42])\end{array}$ & English & $\mathrm{X}$ & $X$ & $\mathrm{X}$ & $\mathrm{X}$ & $\mathrm{X}$ & $\mathrm{X}$ & $\mathrm{X}$ \\
\hline $\begin{array}{l}\text { Chronic Sinusitis } \\
\text { Survey (CSS) } \\
\text { (Gliklich, [13] }\end{array}$ & $\begin{array}{l}\text { English, } \\
\text { Chinese, } \\
\text { Norwegian }\end{array}$ & $\mathrm{X}$ & $\mathrm{X}$ & $\mathrm{X}$ & - & $\mathrm{X}$ & $\mathrm{X}$ & $\mathrm{X}$ \\
\hline $\begin{array}{c}\text { Rhinosinusits quality } \\
\text { of life survey } \\
\text { (RhinoQoL) (Atlas, } \\
\text { [50]) }\end{array}$ & English & $\mathrm{X}$ & $\mathrm{X}$ & $\mathrm{X}$ & - & $\mathrm{X}$ & $\mathrm{X}$ & $\mathrm{X}$ \\
\hline $\begin{array}{l}\text { Sino-Nasal Outcome } \\
\text { Test } 20 \text { (SNOT-20) } \\
\text { (Piccirillo, [52]) }\end{array}$ & English & - & $\mathrm{X}$ & $\mathrm{X}$ & - & $\mathrm{X}$ & $\mathrm{X}$ & $\mathrm{X}$ \\
\hline $\begin{array}{l}\text { Sino-Nasal Outcome } \\
\text { Test } 20 \text { German } \\
\text { Adapted Version } \\
\text { (SNOT-20 GAV) } \\
\text { (Baumann, [58]) }\end{array}$ & German & $\mathrm{X}$ & $\mathrm{X}$ & $\mathrm{X}$ & $\mathrm{X}$ & $\mathrm{X}$ & $\mathrm{X}$ & $\mathrm{X}$ \\
\hline
\end{tabular}


without reduction or loss of smell for more than 12 weeks without complete resolution of symptoms.

Checking all disease-specific instruments for the covering of the major symptoms of CRS we found that the most frequently used instruments (Sino-Nasal Outcome Test, SNOT-20; Chronic Sinusitis Survey, CSS) do not query all these symptoms. Both instruments do not inquire for reduction or loss of smell. Furthermore, the item "nasal obstruction is not included in the SNOT-20. Nearly all the other instruments cover all major symptoms of CRS (see Table 2).

As a validation process was not performed in all the instruments psychometric appropriateness for the use of those instruments in QOL measurements in CRS patients is not assured. Only four of eleven instruments cover all the requirements (Table $\mathbf{2}$ ).

\section{REFERENCES}

[1] Pade J. Sinusitis. Eine ernst zu nehmende Erkrankung. HNO 2005; DOI 10.1007/s00106-005-1227-0.

[2] Pleis JR, Coles R. Summary health statistics for US adults: Nation Health Interview Survey, 1998. National Center for Health Statistics. Vital Health Stat 2002; 10: 1-113.

[3] Becker DG. Sinusitis. J Long Term Eff Med Implants 2003; 13: 175-94.

[4] Gesundheitsberichterstattung des Bundes. Available from: http://www.gbe-bund.de/ [Accessed on October 13, 2009].

[5] Ray NF, Baraniuk JN, Thamer M, et al. Healthcare expenditures for sinusitis in 1996: contributions of asthma, rhinitis, and other airway disorders. J Allergy Clin Immunol 1999; 103: 408-14.

[6] Metson R, Gliklich RE. Clinical outcome of endoscopic surgery for frontal sinusitis. Arch Otolaryngol Head Neck Surg 1998; 124: 1090-6.

[7] Goodale RL. Some causes of failure in frontal sinus surgery. Ann Otol 1942; 51: 648 .

[8] Iro H, Mayr S, Wällisch C, Schick B, Wigand ME. Endoscopic sinus surgery: its subjective medium-term outcome in chronic rhinosinusitis. Rhinology 2004; 42: 200-6.

[9] Sobol SE, Wright ED, Frenkiel S. One-year outcome analysis of functional endoscopic sinus surgery for chronic sinusitis. J Otolaryngol 1998; $27: 252-7$

[10] Stammberger H, Posawetz G. Functional endoscopic sinus surgery. Concept, indications and results of the Messerklinger technique. Eur Arch Otorhinolarngol 1990; 247: 63-76.

[11] Ware JE, Sherbourne CD. The MOS 36-Item Short-Form Health Survey (SF-36). I. Conceptual framework and item selection. Med Care 1992; 30: 473-83.

[12] Garratt A, Schmidt L, Mackintosh A, Fitzpatrick R. Quality of life measurement: bibliographic study of patient assessed health outcome measures. BMJ 2002; 324: 1417-22.

[13] Gliklich RE, Metson R. Effect of sinus surgery on quality of life. Otolaryngol Head Neck Surg 1995; 117: 12-7.

[14] Winstead W, Barnett SN. Impact of endoscopic sinus surgery on global health perception: an outcomes study. Otolaryngol Head Neck Surg 1998; 119: 486-91.

[15] Baumann I, Blumenstock G. Impact of gender on general healthrelated quality of life in patients with chronic sinusitis. Am J Rhinol 2005; 19: 282-87.

[16] Khalid AN, Quraishi SA, Kennedy DW. Long-term quality of life measures after functional endoscopic sinus surgery. Am J Rhinol 2004; 18: 131-6.

[17] Ragab SR, Lund VJ, Scadding G. Evaluation of the medical and surgical treatment of chronic rhinosinusitis: a prospective, randomised, controlled trial. Laryngoscope 2004; 114: 923-30.

[18] Ware J Jr, Kosinski M, Keller SD. A 12-Item Short-Form Health Survey: construction of scales and preliminary tests of reliability and validity. Med Care 1996; 34: 220-33.

[19] Akarcay M, Kizilay A, Miman MC, Cokkeser Y, Ozturan O. The effect of endoscopic sinus surgery on quality of life. Kulag Burun Bogaz Ihtis Derb 2003; 11: 65-71.
[20] Alobid I, Bernal-Sprekelsen M, Mullol J. Chronic rhinosinusitis and nasal polyps: the role of generic and specific questionnaires on assessing ist impact on patient's quality of life. Allergy 2008; 63: 1267-79.

[21] Landgraf JM, Abetz L, Ware JE. The CHQ user's manual. 1st ed. The Health Institue, New England Medical Center; Boston, Mass. 1996.

[22] Waters E, Salmon L, Wake M. The parentform Child Health Questionnaire in Australia: Comparison of reliability, validity, structure, and norms. J Ped Psychol 2000; 25: 381-91.

[23] Cunningham JM, Chiu EJ, Landgraf JM, Gliklich RE. The health impact of chronic recurrent rhinosinusitis in children. Arch Otolaryngol Head Neck Surg 2000; 126: 1363-8.

[24] Robinson K, Gatehouse S, Browning GG. Measuring patien benefit from otorhinolaryngological surgery and therapy. Ann Otol Rhinol Laryngol 1996; 105: 415-22.

[25] Bhattacharyya N, Kepnes LJ. Economic benefit of tonsillectomy in adults with chronic tonsillitis. Ann Otol Rhinol Laryngol 2002; 111: 983-8.

[26] Fahy C, Nikolopoulos TP, O'Donoghue GM. Acoustic neuroma surgery and tinnitus. Eur Arch Otorhinolaryngol 2002; 259: 299301.

[27] McKiernan DC, Banfield G, Kumar R, Hinton AE. Patient benefit from functional and cosmetic rhinoplasty. Clin Otolaryngol 2001; 26: 50-2.

[28] Salhab M, Matai V, Salam MA. The impact of functional endoscopic sinus surgery on health status. Rhinology 2004; 42: 98 102.

[29] Baumann I, Blumenstock G, Klingmann C, Praetorius M, Plinkert PK. Subjektive nutzenbewertung 1 jahr nach funktioneller endonasaler nasennebenhöhlenoperation bei patienten mit chronischer rhinosinusitis. HNO 2007; 55: 858-61.

[30] Newton JR, Shakeel M, Ram B. Evaluation of endoscopic sinus surgery by Glasgow benefit inventory. J Laryngol Otol 2008; 122: 357-60.

[31] Fairley JW, Yardley MPJ, Durhan LH. Reliability and validity of a nasal symptom questionnaire for use as an outcome measure in clinical research and audit of functional endoscopic sinus surgery. Clin Otolaryngol 1993; 18: 436-7.

[32] Lund VJ. Inferior meatal antrostomy: fundamental considerations of design and function. J Laryngol Otol Suppl 1988; 15: 1-18.

[33] Fairley JW. Available from: http://www.entkent.com/mschapter4. html [Accessed on October 15, 2009].

[34] Arunachalam PS, Kitcher E, Gray J, Wilson JA. Nasal septal surgery: evaluation of symptomatic and general health outcomes. Clin Otolaryngol 2001: 26: 367-70.

[35] Douglas SA, Marshall AH, Walshaw D, Robson AK, Wilson JA The development of a general nasal patient inventory. Clin Otolaryngol 2001; 26: 425-9.

[36] Benninger MS, Senior BA. The development of the Rhinosinusitis Disability Index. Arch Otolaryngol Head Neck Surg 1997; 123: 1175-9.

[37] Catalano P, Roffman E. Outcome in patients with chronic sinusitis after the minimally invasive sinus technique. Am J Rhinol 2003 17: 17-22.

[38] Birch DS, Saleh HA, Wodehouse T, Simpson IN, Mackay IS Assessing the quality of life for patients with chronic rhinosinusitis using the Rhinosinusitis Disability Index. Rhinology 2001; 39: 191-6.

[39] Mace J, Michael YL, Carlson NE, Litvack JR, Smith TL. Effects of depression on quality of life improvement after endoscopic sinus surgery. Laryngoscope 2008; 118: 528-34.

[40] Soler ZM, Mace J, Smith TL. Fibromyalgia and chronic rhinosinusitis: outcomes after endoscopic sinus surgery. Am J Rhinol 2008; 22: 427-32.

[41] Tahamiler R, Edizer DT, Canakçioğlu S. The validity of the Rhinosinusitis Disability Index in chronic sinusitis. Kulak Burun Bogaz Ihtis Derg 2007; 17: 138-42.

[42] Kay DJ, Rosenfeld RM. Quality of life for children with persistent sinonasal symptoms. Otolaryngol Head Neck Surg 2003; 128: 1726.

[43] Rudnick EF, Mitchell RB. Improvements in quality of life in children after surgical therapy for sinonasal disease. Otolaryngol Head Neck Surg 2006; 134: 737-40. 
[44] Rudnick EF, Mitchell RB. Long-term improvements in quality-oflife after surgical therapy for pediatric sinonasal disease. Otolaryngol Head Neck Surg 2007; 137: 873-7.

[45] Fahmy F, McCombe A, Hicklin L. Outcome Measures for endoscopic sinus surgery. Proceedings of the $4^{\text {th }}$ European Congress of Oto-Rhino-Laryngology, Head and Neck Surgery, Monduzzi Editore, Milano 2000; vol. 1: pp. 397-402.

[46] Fahmy FF, McCombe A, McKiernan DC. Sino nasal assessment questionnaire, a patient focused, rhinosinusitis specific outcome measure? Rhinology 2002; 40:195-7.

[47] Metson RB, Gliklich RE. Clinical outcomes in patients with chronic sinusitis. Laryngoscope 2000; 110 (Suppl 94) 94: 24-8.

[48] Wang PC, Tai CJ, Chu CC, Liang SC. Translation and validation assessment of the Chinese version of the chronic sinusitis survey. Chang Gung Med J 2000; 25: 9-15.

[49] Wang PC, Chu CC, Liang SC, Tai CJ. Cost-utility analysis for endoscopic sinus surgery. Otolaryngol Head Neck Surg 2004; 130: 31-8.

[50] Atlas SJ, Metson RB, Singer DE, Wu YA, Gliklich RE. Validity of a new health-related quality of life instrument for patients with chronic sinusitis. Laryngoscope 2005; 115: 846-54.

[51] Piccirillo JF, Edwards D, Haiduk A et al. Psychometric and clinimetric validity of the 31-item rhinosinusitis outcome measure (RSOM-31). Am J Rhinol 1995; 9: 297-306.
[52] Piccirillo JF, Merritt MG Jr, Richards ML. Psychometric and clinimetric validity of the20-Item Sino-Nasal Outcome Test (SNOT-20). Otolaryngol Head Neck Surg 2002; 126: 41-7.

[53] Woodworth BA, Joseph K, Kaplan AP, Schlosser RJ. Alterations in eotaxin, monocyte chemoattractant protein-4, interleukin-5, and interleukin-13 after systemic steroid treatment for nasal polyps. Otolaryngol Head Neck Surg 2004; 131: 585-9.

[54] Deal RT, Kountakis SE. Significance of nasal polyps in chronic rhinosinusitis: symptoms and surgical outcomes. Laryngoscope 2004; 114: 1932-5

[55] Anderson ER, Murphy MP, Weymuller EA Jr. Clinimetric evaluation of the Sinonasal Outcome Test-16. Student Research Award 1998. Otolaryngol Head Neck Surg 1999; 121: 702-7.

[56] Brown J, Hopkins C, Slack R, et al. The National Comparative Audit of Surgery for Nasal Polyposis and Chronic Rhinosinusitis. Clinical Effectiveness Unit. The Royal College of Surgeons of England, London 2003.

[57] Fokkens W, Lund V, Mullol J. European Position Paper on Rhinosinusitis and Nasal Polyps group European position paper on rhinosinusitis and nasal polyps 2007. Rhinology 2007; 45(Suppl 20): 1-136.

[58] Baumann I, Blumenstock G, DeMaddalena H, Plinkert PK, Piccirillo JF. Validierung des Sino-Nasal Outcome Test-20 German Adapted Version (SNOT-20 GAV) zur Messung der Lebensqualität bei Patienten mit chronischer Sinusitis. HNO 2007; 55: 42-7.

Received: July 25, 2009

Revised: December 16, 2009

Accepted: December 18, 2009

(C) Ingo Baumann; Licensee Bentham Open

This is an open access article licensed under the terms of the Creative Commons Attribution Non-Commercial License (http: //creativecommons.org/licenses/by$\mathrm{nc} / 3.0 /$ ) which permits unrestricted, non-commercial use, distribution and reproduction in any medium, provided the work is properly cited. 